\title{
HEALTHY AND SOMEWHAT WEALTHY: THE LIVED EXPERIENCE OF SUCCESSFUL AGING
}

\begin{abstract}
ANDRADA TOBIAS ${ }^{1}$
ABSTRACT. The idea of being active, healthy, happy and independent as long as is possible is strongly promoted in public discourse and in aging policies. Starting from the idea of investigating the serious leisure practices of the elderly, I sought to develop a qualitative research that captures perceptions and normative attitudes regarding the perceived and lived experience of aging. The study offers insights into the socially constructed nature of successful aging, by critically exploring the relation between the practice of Tai-Chi, considered a serious leisure activity among older adults, and the neoliberal ideology. During my fieldwork I conducted 14 in-depth semi-structured interviews and I have analyzed a specific typology of subjects - 'healthy and somewhat wealthy' as one of the respondents described himself - motivated by the fact that this category of the elderly is much more likely to internalize and promote neoliberal ideology. The goal of my fieldwork research was to determine how seniors operationalize the concept of successful aging and what strategies they use in order to ensure their experience matches their expectations. I also chose to focus on the way elders embrace a serious leisure perspective, which promises to give them a sense of purpose and progress. As shown by the accounts of the participants in the study, the need to be active, independent, healthy, and cheerful determine individuals to work with their own self and seek to engage in serious leisure activities.
\end{abstract}

Keywords: successful aging, active aging, serious leisure

\section{Introduction}

In the coming years, the percentage of people over 65 will increase from 29.6\% in 2016 to $51.2 \%$ in 2070 (EU Aging Report: 2018). The growing percentage of the elderly has already produced major changes in the perception of the organization and administration of personal care that are reflected in the politics of aging. For example, Active Aging: A Policy Framework developed by the

1 Babeș-Bolyai University, andrada.tobias@ubbcluj.ro. 
World Health Organization (2002) encourages a lifestyle specific to the middle class that involves: an active life, independent and as healthy as possible; encourages spending as much time as possible on productive or meaningful recreation or volunteering (that means serious leisure). The current trend, as aging to become more of an individual risk and less of a collective responsibility (Rudman, 2015), means that increasing numbers of people are compelled to care for themselves, whether economically or physically, as they age. As I will try to present, the involvement in serious leisure activities contributes to this (personal and societal) plan. These changes are relevant to a biopolitical consideration of aging because they shift the parameters within which people experience the trajectories and transitions that punctuate their lives (Neilson, 2012).

Starting from the investigation of serious leisure practices among the elderly, I sought to develop a qualitative research that captures perceptions about how aging should be perceived and lived. I have contextualized Tai-Chi practice (considered a serious leisure activity) among older adults by critically exploring it in relation to the neoliberal context of life. More clearly, the study offers insights into the socially constructed nature of successful aging through leisure under neoliberalism. During my fieldwork I have analysed a specific typology of subjects - 'healthy and somewhat wealthy' as one of the respondents described himself - that can clearly illustrate how some of the prerogatives of neoliberal ideology are transmitted to the elderly and internalized by them. As I will try to show, the need to be active, independent, healthy and if possible cheerful, determines individuals to work with their own self and seek to engage in serious leisure activities.

The concepts of "serious leisure" (Stebbins, 1982) and "successful aging" (Roke and Kahn, 1987) will be discussed in this text. The two have been developed somewhat in the same climate and started from a common ground: that of promoting an active lifestyle, engaging in productive activities, developing the ability to cope (alone) with difficult situations in life, independence and a healthier life (both physically and mentally). Both visions can be applied to a specific population that benefits from decent living conditions, good health and lives in a certain social and cultural climate. Therefore, the application of the concepts can work only in the analysis undertaken on the existing middle class in capitalist societies, highly industrialized and technological developed (Rudman, 2015), in which the family dependency ties are already weakened. Neither perspective discusses at all about precarious individuals, marginalized people or those who have not already adopted a lifestyle specific to the logic of developed capitalism. As I will try to show, the two perspectives, very often embraced in the development of policies for the elderly are somewhat superficial, trying to highlight the benefits of an active, productive and independent lifestyle, omitting explanations of the contexts in which people's lives take place and the inequalities between individuals. 


\section{The link between Successful Aging and Serious Leisure}

Over the last half century, several theories have attempted to capture the essence of what it means to age well. As we know, aging and especially aging well are socially constructed phenomenon. Our perception on aging is influenced by societal expectations, culture and personal experiences. The concept of "old age" has historically been defined through governmental policies. In this respect, concepts such as "active aging" (World Health Organization, 2002) and "successful aging" (Havighurst, 1961; Rowe \& Kahn, 1987, 1997) have begun to be taken seriously and to replace the older paradigms such as disengagement theory, that looked at the negative aspects (such as disease, degradation, marginalization).

Policy agendas have come to dominate in the current global environment of disinvestment in pensions, health services and so on (Neilson, 2012). More clearly, policy agendas emphasize the need for individuals and communities to supplement, or even to replace, government efforts to support aging costs. This contributes to a social atmosphere in which individual investments in health and well-being are encouraged. One of the directions of political agendas advocates for independent living and assumes that older people have the opportunity (and are urged) to live and manage themselves (Ney, 2005) in optimal conditions. Another political provision discusses non-discrimination of people in the labor market and supports the involvement of the elderly in paid work for as long as possible (idem); if paid work is not a feasible option, older people are encouraged to get involved in volunteering (which is classified as serious leisure). The list of examples can go on, but what is essential to remember is that these aging policies cannot be universally adopted and are valid for a fairly small niche of individuals - healthy, who work for pleasure or for maintaining occupational prestige, who do not they have other duties such as caring for extended family members, and who do not have a severely impaired state of health. For this research, I talked exactly with those people who fit perfectly with the profile described, to show how this paradigm has been incorporated.

As I mentioned before, there is a wide global variation in terms used to encapsulate the notion of "aging well". Successful aging and active aging are the most popular and also ubiquitous concepts in social research and public policy (Sao Jose et al., 2017) that are linked to this notion. Both concepts derive from the same scientific root, the activity perspective and sometimes, the two terms are strongly used as synonyms (Foster and Walker, 2014). The concept of successful aging is multidimensional and has begun to be important for researchers interested in describing the quality of life of the elderly. The term was first introduced by Robert Havighurst in 1961 and has its roots in the Activity Theory. It began to be popular in the field of gerontology, in public discussions and later in political 
agendas (Lamb, 2014). Then it gained even more popularity after being taken over by John Rowe and Robert Kahn, initially at a seminar held in 1987 and then in the book "Successful Aging" published in 1988. The book focuses on the analysis of the results of the study MacArthur Foundation Study of Aging in America aimed at identifying the factors that contribute to maintaining the physical and mental vitality of the elderly. The authors argue that the golden age involves both loss and gain, but individuals must look to those that involve active engagement with life. The two make a clear distinction between usual and successful aging, both referring only to those elderly people who do not show severe pathologies. Following the popularity, but also the criticism received over a decade, in 1997, the two authors published a new article in which they seek to clarify, once again, their vision of what successful aging means:

We hoped that the distinction between two groups of non-diseased older persons - usual (non-pathologic but high risk) and successful (low risk and high function) - would help to correct those tendencies, stimulate research on the criteria and determinants of successful aging, and identify proper targets for interventions with "normal" elderly (1997:433).

For Rowe and Kahn $(1987,1988,1997,2015)$, successful aging includes three essential components: low probability of disease and disease-related disability, high cognitive and physical functional capacity, and active engagement with life. There is a hierarchy between the three components, and successful aging cannot include only one or the first two, but refers to the relationship between all three.

Successful aging theory is so popular due to the change of vision on the problematization of theories about the elderly from disease and decline, to a discipline that emphasizes health, workforce and a pro-active attitude. Although it has received (and continues to receive) much appreciation, successful aging theory still has its share of criticism and controversy. A first criticism was that it cannot be applied universally and that those elderly people who face certain problems (health, material, social) are not included in it (Neilson, 2012; Nimrod and Shrira, 2014; de Sao Jose et al., 2017). Simultaneously with this critique, a large number of studies have been developed and have shown that, despite the fact that certain characteristics are seen among the elderly may suggest that successful aging theory does not stand, successful aging may be achieved (Hochhalter et al., 2011). In other words, successful aging theory cannot be regarded as a theoretical model (Hartley et al., 2018) and it is more suitable to understand that it places more emphasis on the results (Rowe and Kahn, 2015). 
Another critique of this theory refers to the fact that the definition of the concept of "successful aging" lacks the perspective (or voice) of the elderly. Theter and Chonody (2019) mention that successful aging was developed "without the input of older adults 'views and experiences or an evaluation of the extent to which the theory's principles and premises adequately depict the lived" (p. 3). The same authors justify their position by presenting several previous studies, in which researchers predefined the factors instead of giving the elderly the opportunity to define what successful aging means for them. Therefore, many of the research results that have been mentioned have inaccurate or questionable results, and this leads Theter and Chonody to say that there is a need for a revision of the working methodology and to give significantly greater power to the perceptions of the elderly. Moreover, elderly groups cannot be understood as homogeneous groups, with people with similar characteristics, but social, cultural, health status, even gender or degree of religiosity must be understood. The perception of successful aging, strongly imbued with the prerogatives of capitalist societies, cannot be universally valid. The promotion of autonomy, interdependence and active life cannot be universally understood as central values that define well-being everywhere in the world (not even among all the elderly in countries with a developed economy). Most often, successful aging is defined not simply by the low probability of disease and high physical and cognitive function, but also by the active psychological ability to engage with life in ways that appear unrelated to social position or status (Katz, 2013). In conclusion, the concept of successful aging has brought great challenges to researchers who have tried to theorize it and include it in analyses. The inconsistency of conceptualization and existing modes of measurement between studies (Katz, Calasanti, 2015), along with the absence of the perspective of the elderly, makes this term quite controversial, giving rise to disagreements over the validity of research (Depp and Jeste, 2006).

I will shortly discuss the concept of "active aging" because is stronger related to the policy framework of Europe. Unlike successful aging, which is primarily a theoretical concept (Timonen, 2016) very popular in the USA, active aging is "primarily a policy concept" (Lassen \& Moreira, 2014: 33 in de Sao Jose et al., 2017) used in response to the aging population in Europe (Timonen, 2016). The World Health Organization (2002) developed this concept as a policy framework to assist governments in promoting and supporting active aging. This policy framework has been dominated by a narrow economic and productivistic perspective that prioritizes the extension of working life, or at least active life (Foster and Walker, 2014). It focuses on the connection of health and activity through six determinants: health and social services; physical; personal; behavioral; social; and economic, with cross-cutting determinants of gender and culture. World Health Organization (2002) defined active aging as: 
the process of optimizing opportunities for health, participation and security in order to enhance quality of life as people age. (...) It allows people to realize their potential for physical, social, and mental wellbeing throughout the life course and to participate in society according to their needs, desires and capacities, while providing them with adequate protection, security and care when they require assistance (WHO, 2002: 12).

A strong critique of the concept of active aging and the policies that include it - to which I adhere - was produced by Virpi Timonen (2016). It starts from the finding that scientists and policy makers often see the elderly as a homogeneous category (with concerns, living conditions and similar statuses) and superficially treats the differences between genders, social classes, religious orientations, ethnicities, etc. She mainly accuses policy makers of asking people to be active and in control of their own lives, while being perceived as individuals who lack agency. So, the critique of active aging is in fact the same as the critique of neoliberalism.

Although the concept is more oriented towards the course of life than successful aging, it still remains defined from an economic and production perspective, underlying the development of European (but also global) policies on aging (de Sao Jose, 2017; Timonen, 2016). Policy agendas have come to dominate in the current global environment of disinvestment in pensions, health services and so on (Neilson, 2012). More clearly, policy agendas emphasize the need for individuals and communities to supplement, or even to replace, government efforts to support aging costs. This contributes to a social atmosphere in which individual investments in health and well-being are encouraged. One of the directions of political agendas advocates for independent living and assumes that older people have the opportunity (and are urged) to live and manage themselves (Ney, 2005) in optimal conditions.

As I said before, in this study I am interested in discussing what the elderly understand by "successful aging" and how it is closely related to serious leisure (including here Tai Chi practice). Before moving on, I think it is necessary to explain the concept of serious leisure, starting from Robert Stebbins' view point. Stebbins' role in structuring the research approach is undeniable; the distinction that the sociologist makes between the concepts of serious leisure and casual leisure can bring additional clarifications regarding the current vision on leisure and makes it easier to understand the presence of leisure forms that contribute to self-rebuilding. Robert Stebbins became interested in leisure analysis in the early 1970s, and most of his work was based on the results of his ethnographic research, interviews, and participatory observations. For Stebbins, leisure can range from occasional, temporary commitments to 
intensive short-term projects to more serious lifelong commitments that require a lot of time, money and energy. He developed a theoretical framework that includes three types of leisure as follows: "casual leisure", "project based leisure" and "serious leisure" (Stebbins, 1982). The last type of leisure is the one that gives the name of the famous Serious Leisure Paradigm (SLP).

Casual leisure is fundamentally focused on hedonism and refers to relatively short or spontaneous activities that bring intrinsic rewards and do not require special training in advance to bring satisfaction to the individual (Stebbins, 1997). Here can be included, for example, watching TV, going out for socializing, but also practices classified as deviant at some point in a society (Rojek, 2005). As it is easy to understand, casual leisure, compared to serious leisure, is considered to be substantially less valued by individuals.

Project based leisure refers to those forms of leisure practiced on a relatively short or occasional term. It tends to be a creative undertaking carried out in free time that involves considerable planning, effort, and sometimes skill or knowledge. Examples of project-based leisure can be: sports events, arts festivals, religious holidays, individual birthdays and national holidays (Stebbins 2006).

The importance of practicing a leisure activity in the category of serious leisure began to be presented through a neoliberal lens by specialists in leisure studies, psychologists, company managers, trainers or pedagogues amid the change of vision on how it would it is desirable that "respectable" individuals should spend their free time for the purpose of "continuous development" and a much clearer defining of the "self". Stebbins describes this as a leisure activity involving knowledge, experience, and specific skills that are opposite to casual leisure. Serious leisure is highly interesting, important and fulfilling to the participant for whom it "embodies such qualities as earnestness, sincerity, importance, and carefulness" (Elkington and Stebbins 2014: 16). According to Stebbins (1982, 1997), six characteristics differentiate serious leisure from casual leisure. These characteristics are: 1) the need to persevere in the respective activity; 2) willingness to develop a career in the field; 3) the need to make an effort to gain knowledge and skills; 4) by practicing this form of leisure, the individual obtains special benefits; 5) acquiring a unique ethos in society; 6) the development of an attractive personal and social identity (Stebbins, 1982).

The fact that serious leisure represents a significant factor of successful aging was developed in a series of writings (Eakman, Carlson, \& Clark, 2010; Ferri, James, \& Pruchno, 2009; Heo et al., 2013; Menec, 2003). Most of them resort to a positivist approach and most often a causal relationship emerged between practicing activities considered serious leisure and their benefits on the subjects. A significant part of the studies came to the following conclusion: "The involvement of older adults in serious leisure activities may serve to facilitate 
successful aging" (Heo et al., 2013: 18). I have not found any research to compare two different samples, or even more importantly, to investigate how easy or difficult it is to get involved in serious leisure activities for elderly populations with different socio-demographic characteristics, marginalized people or people in precarious conditions of life. All the studies I have identified are aimed at a rather niche audience - belonging to a middle-high socioeconomic status - that's why it is rather inappropriate to generalize the analysis to the entire population.

All the changes in the way the elderly should be perceived are due to a combination of factors related to the de-responsibilization of states towards individuals, the change of responsibilities between states and markets, global migration and the development of geriatric medicine (Sao Jose et al., 2017). This new vision of old age has been successfully embraced by a specific typology of the elderly - who do not face a precarious financial situation or a weakened state of health - and tends to become a pattern that is intended to be universally imposed. As Nikolas Rose describes in "The Politics of Life Itself: Biomedicine, Power, and Subjectivity in the Twenty-First Century" (2007), biomedicine came to view the notion of health as a personal social-ethical imperative. Thus, we come to meet branches of the silver industry, specialized leisure programs, fiction, wellness that focus on the continuous concern of individuals for their own self. This also creates an increasing responsibility for one's own health, for the maintenance and optimization of the body and mind, throughout life. Although aging can involve (and often does involve) the emergence of disabilities that restrict participation in the circuit of capitalist valorization, individuals are encouraged to contribute through voluntary work, charity, and self-practice to a style of active and independent life, which burdens neither the other members of the family, nor the state. In this context, self-control - promoted by successful aging paradigm and serious leisure perspective - becomes an important tool linked to the economic sector and political rules.

Both concepts - serious leisure and successful aging - are strongly imbued with a neoliberal logic. Neoliberalism refers not only to the idea of controlling and disciplining individuals, but also to the idea of making subjects more efficient, docile, entrepreneurial, happier, fulfilled, and confident (Rose, 1999). This new form of government involves power structures through which the government rallies to the abilities, skills and personal visions of individuals and manages to create a sense of freedom, relying precisely on the self-responsibility of subjects. In this context, individuals develop a strong self-control, out of the desire to succeed and the appreciation of others, trying to be more efficient and responsible for their own lives, without looking for possible culprits outside their own person (Miller and Rose, 2008). Neoliberalism involves subtle forms of control, much more effective compared to the forms of classical liberalism governmentality, which can be understood as a system of imposing authority from top to bottom (Freeman, 2007; Hefner, 2010). 
For the present paper, it is important to understand that "successful aging" and "serious leisure" concepts as biopolitics (de Sao Jose et al., 2017: 49). In a very simplified understanding of the term, biopolitics refers to the style of government that regulates populations through "biopower" (Foucault, 1988), that means the application and impact of political power on all aspects of human life. Biopower emphasizes how our life abilities and qualities (e.g. the ability to manage independent, volunteering, the involvement in outdoor activities) are key objects of exploitation - particularly under neoliberalism (Fleming, 2014). In addition to the fact that the two discourses - successful aging and active aging promote certain disciplinary practices, they also guide certain technologies technologies of the self ${ }^{2}$ - through which individuals act on their own lives and bodies, setting new standards for what "aging well" means.

The emergence of new strategies of activation and responsibilization of individuals are increasingly obvious; certain conceptions of subjectivity from psychology are now central and act in the name of the idea of independence and happiness (Binkley, 2014). To be considered a "successful aging" person, you have to be independent, involved in the community (volunteering or working) in a good health position (that can be improved through active leisure activities). These demands are invading the public speeches and are reflected in policies that strategically target areas of intervention that are identified and monitored using specific technological measures, like: rates of illness or disability, prevention measures (Osborne, 1997). The contemporary tendency is that ageing to become more of an individual risk and less of a collective responsibility. This means that increasing numbers of people are compelled to care for themselves, whether economically or physically, as they age. These changes are relevant to a biopolitical consideration of ageing because they shift the parameters within which people experience the trajectories and transitions that punctuate their lives (Neilson, 2012:45).

\section{Methodology}

For this research, I focused my attention on two relevant topics that emerged from fieldwork data: 1) what do seniors understand by successful aging and what strategies do they use in order to age well?; and 2) the way the elders embrace a serious leisure perspective. During the last year, I have

2 [Technologies of the self] permit individuals to effect by their own means or with the help of others a certain number of operations on their own bodies and souls, thoughts, conduct, and way of being, so as to transform themselves in order to attain a certain state of happiness, purity, wisdom, perfection, or immortality (Foucault, 1988:18). 
conducted in-depth semi-structured interviews with 14 participants. The first three participants were recommended by the manager of a day center for elderly; after this first step, I used de snow ball method of sampling and the respondents put me in contact with other people. Their ages ranged from 69 to 88 years. A first criterion according to which the interviews that are part of this research were selected was that the elderly declare that they are satisfied or very satisfied with their current life. The other criteria according to which the respondents were chosen included the following: all had residency in the urban environment, all had a non-manual profession / trade that required at least secondary educational training (i.e. at least high school graduates) and all visited at least once one of the existing day centers for the elderly in their locality. They were asked to provide background demographic information on their marital status, living conditions, education, years from retirement, their former profession, their current health status. Of the 14 people selected, 9 were widows ( 8 women and one man) and 5 lived with their partner. None of them shared the home with other extended family members, such as children, grandchildren, or other relatives (except the partner, where applicable). In addition to the interviews I conducted, I was engaged in more informal participant observation research with several older persons gardening near the building and other daily life events. The interviews (but also some informal discussions) focused on the subjects' life story, on daily practices and social relations, on their experiences and attitudes regarding leisure, and their own visions of what successful aging and active aging would entail.

\section{The meaning of successful aging through the lens of 'healthy and somewhat wealthy' adults}

Starting from the newest directions of study, which discusses a change of vision on the meanings given to leisure ${ }^{3}$, I started a fieldwork research on leisure practices among older people. As I mentioned in the methodological section, through the fieldwork I have undertaken over the last year, I tried to understand the perception of the elderly on the concept of successful aging. The biggest challenge I faced was finding the most appropriate terms to use in the interviews so that I would be as impartial as possible and avoid labelling. I realized

3 Leisure is seen as time and space for the acquisition of personal pleasures and for the cultivation of the self and is strongly links with the area of positive psychology. Starting from Csikszentmihalyi (1997) the definition of leisure places a very strong emphasis on motivations, beliefs and perceptions at the individual level and loses sight of the social, historical or cultural context. 
that it is incredibly difficult to use a term that refers to the population over the age of 65 without any connotations, such as the terms "elderly", "senior citizen", not to mention the term "old man". Although for this choice I can be easily criticized from a methodological point of view, I decided to avoid a very clear wording when referring to my study population and to be very careful about the terminology used by the person I was talking to.

I would like to mention once again, all the people I talked to were people who live alone or with their partner, manage to move freely and provide everything they need, and are not financially dependent. I intentionally selected these so-called people representative for the successful aging model, but not in the idea of supporting the perspective, but to illustrate how it was incorporated into the daily routine of 14 people over 65 in Romania. With the exception of two ladies, all the other people had a very well-established daily routine, which included in the first part of the day doing household chores (several mentions were related to helping the extended family: children, grandchildren). All the activities related to personal care and home care are exclusively the concern of these people, which makes the daily schedule quite demanding (but natural and necessary from their perspective). What came out strong in all the interviews was a strong desire to preserve dignity and integrity, associated with a high selfesteem, a strong sense of meritocracy, accompanied by the idea of selfrealization by personal efforts:

In my condition, healthy and somewhat wealthy, is important to maintain an active life. That keeps me alive. I worked constantly all my life with my mind, with my soul and with my body to have my current lifestyle [...] I am sure that everyone deserves a peaceful elderly but most have not built it in time. I know that I am a lucky person but I started to work for my luck in the 90's when I was still young [he was an artist and after 1990 he collaborated with various theaters in Europe and mastered another way of thinking] (Liviu, 76, artist).

Since I retired, I've been doing what I love most of the time. My family is all set up. I have arranged my life since I was still in power. In fact, I still am, but I use my powers to do what I like. I taught my children to be independent and that is the claim I have from myself. I don't want to become a burden to them, because they weren't for us either and from the age of 18-20 they managed on their own. What are you supposed to do?! That means a good start, ma'am! (Peter, 74, former engineer).

In general, the concept of successful aging has been associated with personal independence. Six of the respondents discussed the fact that from a certain age, success is measured in the ability to still be able to achieve everything necessary for the self and not to be responsible (anymore) for others life. 
Independence, so strongly valued and internalized in the case of the people who participated in this research, is a relatively recent feature encountered in Romanian society, which is characterized rather by close relations of intergenerational solidarity. The report of the Population Policy Acceptance survey (2006) shows that Romanians rely heavily on family support, both descending (from parents to children) and ascending (from children to parents) (Hărăguș, 2016: 53). A feature of neoliberal ideology, also encountered in theorizing the concept of successful aging, is to move the concern from caring for others to self-care in the first place. This fact brings a very strong self-responsibility and at the same time a de-responsibility of the everyone towards others. The thought of helplessness is the most torturous for most respondents.

Modesty is nonsense! I am proud of myself that I have aged successfully (laughs). I am 80 and I can take care of myself, I don't take pills and I can afford some vacations. After my husband died, I thought I wouldn't go anywhere alone because I had never been alone somewhere. And my daughter took me on a vacation, but we have different expectations and it was uncomfortable for both. Then I said for myself: I have to find a way to travel, to fill confortable and to socialize. Then I discovered a travel agency and since then I have made over 20 trips in the country and abroad [in the 6 years with a group of elderly people] (Ana, 80, former beautician).

[...] No one expects anything of me anymore. I've done so much in life that now there's no need for anyone to expect me to. I don't have any expectations from others either. You will see, but only after you grow old, that if you want to do well, you give up expectations. I think I still have an expectation or maybe just a desire for my grandchildren to call me at least once a week. It usually happens even more often. I never call them so as not to disturb them (Steliana, 79, former engineer).

Successful aging also represents in the vision of the interlocutors, beyond independence, a balanced life without health problems. Disease avoidance is the direct concern of the subject whose task it is to constantly monitor and take the necessary measures in time. As some of the respondents said, no one else is responsible for the personal life and health conditions (with the exception of genes).

If you know your medical history, not only yours, but that of the whole family and you know what pathologies you can face, you can face the health problems head-on, but as early as possible. The care taken from youth, to old age and temperance, make old age easy to bear. (Gela, 78, former teacher). 
In addition to regular medical check-ups, one of the solutions to maintain a healthy life, as it emerged from the interviews, is to practice physical activities and a "moderate" active lifestyle. The preoccupation of individuals with their own state of health, physical and mental, facilitated the performance of some forms of serious leisure. These practices are used by most seniors as strategies for aging well and represent a good proof of self-care. Among these practices were mentioned in interviews: Tai Chi, yoga, meditation, gardening (plant care), photography classes, theater classes or pottery. It is easy to notice that the range of activities is very rich, so I decided to focus only on Tai Chi, included in the category of "positive spirituality".

Tai Chi is a recreational practice, in the category of serious leisure and often recommended for a better tonus and health not only in the eastern part of the earth, where the tradition comes from, but also in western countries (Lee, 2017). A tradition of these practices has existed in Western Europe for about two or three decades, but it has been embraced for at least 8 years, among the offers addressed to day centers for the elderly in Romania. Therefore, Tai Chi is frequently presented as a suitable social leisure activity and also a training exercise for elderly adults (Li, 2019; Yao, 2015). But the purpose of this text is not to make a value judgment on this practice, but to understand how Tai Chi practitioners (or those of other serious leisure activities) articulate a strong discourse imbued with the idealized vision of the elderly, found in Successful Aging Theory, and which supports the neoliberal ideology.

In selecting the people for this research, I used the snowball method which, of course, led me to people with a certain profile and with somewhat similar recreational practices. I talked to 8 people from two groups of Tai Chi. One of the groups is a formal one, relatively well known in town and it is frequented by people of all ages. The other group has no any formal character, but represents a sort of community for the members. All the respondents stated that they show the benefits of Tai Chi from the beginning and wanted to deepen their theoretical and practical knowledge as soon as possible. Most valuable aspects of practicing Tai Chi that were mentioned by them can be summarize as: a better tonus and a visible health improvement without exterior contribution (like pills or medical procedures); a new way of thinking about what is important in life (a stronger focus on improving issues that can be directly addressed by the respondent); a way to gain self-satisfaction and self-appreciation (acquiring a state of well-being through interior resources); a way to fill time in a pleasant way or "the most pleasant time to be active"; assists them in coping with the new realities of being a retiree. 
I tell you concretely that since I do Tai Chi, my cholesterol level has dropped. It's logical because I'm active, active again! And you know... I'm in peace with my age. I know I'm doing well [by practicing Tai Chi] and I find a purpose in life [...] After a life on the move, on the road, when I retired I realized that I lost my purposes. It was awful (Sanda, 73, former secretary).

Half of the respondents have their first contact with Tai Chi seven years ago, at the center for elderly. The manager of the institution invited a Tai Chi master for one of the socialization and leisure services. During that period there were sufficient funds within the center and also initiatives to propose a wide range of activities, which aimed, among other things, to identify the most attractive activities for beneficiaries. Until the elderly took part in the physical activity, the Tai Chi master gave a lecture and informed the participants about this practice. Few of them have decided to continue and find out more details. As one of the interviewees stated, Tai Chi did not necessarily enjoy popularity because it is a practice that involves a certain level of "knowledge and depth, which was not possible for everyone" and because of this the program was canceled. What was also been mentioned is that some of the acquaintances did not understand the practice and considered it "sectarian". After a few meetings, the center stopped the collaboration and some of the elderly decided to continue these exercises and contacted the Tai Chi suppliers directly. According to one of the respondents, 7 of those who first came into contact with this practice at the day center, decided to contact the master directly and then attend Tai Chi, inside a specialized institution (a center for personal and spiritual development). Some of them decided to put an end to this practice after a few months, and two ladies joined another informal Tai Chi group. From this group, I selected 5 of them for the interviews.

In addition to those who first made contact with Tai Chi at the day center, others were attracted by this practice because of their friends, either in the formal or informal group. The informal group consists exclusively of women, although they did not want to be a gendered group. The initiators of the group came off from one of the formal groups and decided to self-organize and practice these activities by the river. Among the practitioners, some have in-depth knowledge of yoga and Tai Chi, and have studied in spiritual development centers (one of them managed to attend an internship in France), others have been influenced by friends or neighbours and are interested in physical movement, without necessarily wanting to deepen the technique. Unlike the formal centers where this activity can be practiced for a fee and with the support of an initiated master (most often with internships in China or other Asian countries), the 
group who meets on the river bank is informal. There is no proper hierarchy here, there are no participation fees and there is no need for an acceptance process; anyone can join the group, regardless of age, training or gender. Beyond the fact that these meetings are seen as an important source of vitality and strengthening of the body, soul and mind, they are also seen as a form of therapy. The members socialize outside these meetings and discuss aspects related to daily life and as one of them said:

We support each other in a new process, in which we mainly fight to change our mentality. You can see many gray, sad, grumpy old women on the street. In my youth I disliked it deeply, now even more. We don't want to be like that! We want our well-being first, and then to our families. One should know that a smiling face can make your day more beautiful! Do you know the Latin proverb 'mens sana in corpore sano'?! We move, we laugh, we talk, and then everyone goes to their houses, to their families, but with a good mood. (Ica, 75, former chemist).

Unlike the riverside activities, those who practice Tai Chi inside the center of spiritual development are regimented in a hierarchical scheme. In addition to the practical sessions - offered during the pandemic on a virtual platform - the masters frequently explain the personal benefits of Tai Chi. At the discursive level, any of the practitioners has the opportunity to become a professional with a lot of work to which are added certain accreditations. To participate in these activities, members pay some fees ( 50 lei or more) so they also become customers. The relationship between master and practitioner captures the market economy logic, in which one is the provider and the other one is the beneficiary of the service. In order to be a valued good, the set price is very important. Therefore, the quality of the service is also highlighted by its financial side.

During my fieldwork I found that there is a close connection between Tai Chi practice and the elderly's concern for their own well-being. All Tai Chi practitioners have a clear vision of the benefits of practicing this activity and are persevering in trying to maintain a routine. The fact that a large part of those who are part of the group shows constancy makes this practice receive an additional connotation, that of a community. The effects of this practice are felt by the interviewed practitioners both on the physical (higher mobility, increased tone) and on the psyche - a unique ethos in society (Stebbins, 1982; 1997) - by finding a so-called inner peace.

[...] Worries, concerns, seem far away. I am encapsulated in a waterproof bubble [during Tai Chi practice]. I get the power to take things differently, much easier, as they come. [...] I had to do something to become again 
who I was before [ my husband's death] and realize for the first time in my life that I was on my own. We are part of another generation where from the care of parents, you end up sharing everything with your husband. I learned the lesson of loneliness, but also to be on my own, only after 67 years. [...] You gain the power to take things around you as they come and learn to regain balance. (Sanda, 73, former secretary).

To practice Tai Chi, the elderly must persevere, to make an effort to gain skills and knowledge, these being specific features of the serious leisure perspective. The justification for choosing the practice of Tai Chi is given by the well-being that this practice produces on those involved - the 5th characteristic of serious leisure. Beyond the well-being and the development of a toned body - the 4th characteristic of serious leisure -, the discussions that develop between the participants continue, sometimes, in other spaces (cafes, personal visits) the 6th characteristic of serious leisure. Tai Chi becomes more than just a recreational practice, but it is the determinant of a new lifestyle (at least for some of those interviewed). These changes favor the development of a new vision of the life and condition of the elderly, accompanied by a strong sense of belonging, not of indebtedness.

What I think needs to be understood is the fact that only a niche population in Romania can be involved in recreational activities such as Tai Chi. Impediments are on the one hand of a logistical nature (inability to contact a master directly), of a cultural and social nature, of a medical nature, but also of an economic nature. Although the practice of Tai Chi does not necessary involve direct financial costs (the case of riverside practitioners), the people involved must show a high degree of availability, but also openness to a new and untraditional lifestyle. In order to be able to participate in these activities on a daily basis, people must have the necessary time, energy and a good health condition (and also money).

Although Tai Chi can be practiced by both women and men, this practice is strongly gendered in Romania. Women show a much greater availability towards these practices compared to men. Being a highly gendered activity, we must also pay attention to one aspect, that of the fact that, again, only a niche population can be engaged, because many of the women in Romania, who are still able-bodied, are burdened by household chores and extended family care. To this aspect is added the traditional vision on the role of women which also covers clothing (wearing pants being in some situations viewed with maximum restraint). So, when we discuss the practice of Tai Chi, as well as other serious leisure activities, it is necessary to understand that the ways of spending free time are conditioned by a set of constraints related to the individual and the 
environment in which he lives, the opportunities that exist in various contexts of life, structural and contextual factors and significant ideologies at the time. Tai Chi practitioners represent the privileged elderly, representatives of the middle class, pioneers in the field, as they may have been in their youth.

I always set the trend. When I was young, I set the trend in fashion. I was getting fabrics, I was getting magazines from the West. I could also have certain freedoms. Those who did an important job, who were someone, I would say we stayed like that today. Of course, I have to have some decency and compare myself to those of my generation. But among the large pile of senile old people, I am by far very good! [Laughs] That's why I'm still alone. It is too difficult to find an old man with a young spirit in Romania. We still have to learn as a nation what it means to be old, but to stay alive. In our country it seems shameful to say that you are fine. We remained fools, as we were before [in communism], locked in and envious of the success of others (Neli, 74, former accountant).

\section{Conclusion}

During my analyses I have tried to show how elements of neoliberal ideology have already been internalized by the privileged categories of the elderly. Following the fieldwork on the "healthy and wealthy" elderly, it was revealed that at least they have already moved away from the traditional model that involved the increased responsibility of younger family members for the elderly. The need to be active, independent, healthy and if possible cheerful, is now a personal responsibility and determines individuals to work with their own self and seek to engage in serious leisure activities.

The way the elders embrace a serious leisure perspective show us what are their expectations regarding leisure seen as time and space to be fruitful for their own development. The importance of practicing a leisure activity in the category of serious leisure began to be presented through a neoliberal lens by specialists in leisure studies, psychologists, company managers, trainers or pedagogues amid the change of vision on how it would be it is desirable that "respectable" individuals should spend their free time for the purpose of continuous development and a much clearer definition of the self. Activities that do not require effort to obtain knowledge, skills and then benefits, which do not have a certain consistency, begin to be strongly devalued, primarily because they do not provide the subject with the necessary development to achieve success. At the same time, there are new demands that require individuals to use their time wisely and conscientiously, and involvement in activities that do 
not benefit the self is perceived almost as a loss, as a waste of a non-renewable resource that is time. The practice of Tai Chi is successfully embraced precisely because it can satisfy all these requirements, being eminently focused on the holistic development of the self.

From my point of view, when conducting research similar to the one presented here, we must not forget that the data are strictly relevant for a population whose standard of living, pre-retirement lifestyle and health, are not, in general, representative for the elderly population in Romania. The fact that this privileged category of the elderly encourages a new lifestyle, precisely through the power of their own example, puts additional pressure on those who fail to meet these requirements. Through a strong meritocratic discourse, seen to an overwhelming extent in the interviews, the "healthy and somewhat wealthy" elderly people justify their current state, both physically and mentally. In their view, one's own well-being is the direct responsibility of the individual, and the importance of structural factors is greatly diminished. Those who fail to meet aging well standards seem to be the ones who have not made sustained efforts in time in order to maintain a decent life and who, at the moment, fail to be active and independent. The reasons for the so-called failure, as the data analyzed have shown, often seem irrelevant or at least blurred.

\section{REFERENCES}

*** "Active Ageing: A Policy Framework". WHO April 2002. http://www.who.nt/ageing/publications/active_ageing/en/.

*** European Commision. The 2018 Ageing Report. Economic and Budgetary Projections for the EU Member States (2016-2070). Institutional Paper 079/may 2018. https://apapr.ro/wp-content/uploads/2018/09/2018-eu-aging-report.pdf.

Binkley. S. (2014). Happiness as Enterprise: An Essay on Neoliberal Life. New York: Suny Press.

Chen, S., Fu, Y. (2008). Leisure Participation and Enjoyment Among the Elderly: Individual Characteristics and Sociability. Educational Gerontology, 34(10):871889. DOI: $10.1080 / 03601270802115382$.

Csikszentmihaly (1997). The masterminds series. Finding flow: The psychology of engagement with everyday life. New York: Basic Books.

Cutler, Neal, E. (2004). Silver Industry: Introduction. Generation, 4(4):6-17.

Eakman, A. M., Carlson, M. E., Clark, F. (2010). The Meaningful Activity Participation Assessment: A Measure of Engagement in Personally Valued Activities. The international Journal of Aging and Human Development. 70(4):299-317.

Fleming, P. (2014). When 'life itself' goes to work: Reviewing shifts in organizational life through the lens of biopower. Human Relations, 67(7): 875-901. 
Ferri, C., James, I. (2009). Successful Aging: Definitions and Subjective Assessment According to Older Adults. Clinical Gerontologist, 32(4):379-388. DOI: 10.1080/ 07317110802677302.

Freeman, C. (2007). The 'Reputation' of Neoliberalism. American Ethnologist, 34(2): 252-267.

Foucault, M. (1988). Technologies of the self. în L. H. Martin, H. Gutman, \& P. H. Hutton (Eds.), Technologies of the self: A seminar with Michel Foucault (16-49). London: Tavistock.

Harper, S. (2019). Living Longer within Ageing Societies. Journal of Population Ageing, 12:133-136.

Haywood, L., \& Henry, I. (1986). Policy Developments in Community Leisure and Recreation: Part 1 - Implications for Management. Leisure Management, 6(7).

Hartley, A., Angel, L., Castel, A., Didierjean, A., Geraci, L., Hartley, J., Hazeltine, E., Lemaire, P., Maquestiaux, F., Ruthruff, E., Taconnat, L., Thevenot C., Touron, D. (2018) Successful aging: The role of cognitive gerontology. Experimental Aging Research, 44:1, 82-93, DOI: 10.1080/0361073X.2017.1398849.

Havighurst, R. J. (1961). Successful Aging. The Gerontologist, 1 (1): 8-13.

Hărăgus, M. (2016). Solidaritatea intergenerationala in situatia corezidentei dintre parinti si copii adulti. In: Muresan, C., Foldes, I. (Eds.) Traiectorii familiale. România în context european. Cluj-Napoca: Presa Universitara Clujeana.

Hefner, R. W. (2010). Religious Resurgence in Contemporary Asia: Southeast Asian Perspectives on Capitalism, the State, and the New Piety. The Journal of Asian Studies, 69(4):1031-1047.

Heller, T., Caldwell, J., Factor, A. (2007). Aging family caregivers Policies and practices. Mental Retardation and Developmental Disabilities Research Reviews, 13: 136 142.

Heo, J., Stebbins, R., Kim, J., Lee, I. (2013). Serious Leisure, Life Satisfaction, and Health of Older Adults. Leisure Sciences, 35(1). DOI: 10.1080/01490400.2013.739871

Hochhalter, A.K., Lee Smith, M., Ory, M.G. (2011). Successful Aging and Resilience: Applications for Public Health and Health Care. In: Resnick B., Gwyther L., Roberto K. (eds.) Resilience in Aging. New York: Springer.

Katz, S.2013). Active and Successful Aging. Lifestyle as a Gerontological Idea. Recherches Sociologique et Anthropologique. 44(1): 33-49.

Katz, S., Calasanti, T. (2015). Critical Perspectives on Successful Aging: Does It "Appeal More Than It Illuminates"? The Gerontologist. 55(1): 26-33.

Lamb, S. (2014). Permanent personhood or meaningful decline? Toward a critical anthropology of successful aging. Journal of Aging Studies. 29: 41-52.

Lee, Y., Chi, I., Palinkas, L. A. (2018). Retirement, Leisure Activity Engagement, and Cognition Among Older Adults in the United States. Journal of Aging and Health. 31(7):1212-1234. doi:10.1177/0898264318767030.

Menec, V. H. (2003). The relation between everyday activities and successful aging: A 6-year longitudinal study. The Journals of Gerontology: Series B: Psychological Sciences and Social Sciences, 58(2), S74-S82. https://doi.org/10.1093/geronb/ 58.2.S74. 
Miller, P., Rose, N. (2008). Governing the Present. Administering Economic, Social and Personal Life. Cambdridge: Polity Press.

Neilson, B. (2012). Ageing, Experience, Biopolitics: Life`s Unfolding. Body\&Society, 18 $(3-4): 44-71$.

Roberts, K. (2006). Leisure in Contemporary Society. CABI Publishing.

Rojek, C. (2005). Leisure theory: principles and practice. Basingstoke: Palgrave Macmillan.

Rose, N. (1999). Governing the Soul. The Shaping of the Private Self. London and New York: Routledge.

Rose, N. (2007). The Politics of Life Itself: Biomedicine, Power, and Subjectivity in the Twenty-First Century.Oxford: Princeton University Press.

Rowe, J. W., \& Kahn, R. L. (1987). Human aging: Usual and successful. Science, 237(4811), 143-149.

Rowe, J. W., \& Kahn, R. L. (1988). Successful Aging. New York: Cambridge University Press.

Rowe J. W., Kahn R. L., (1997). Successful aging. The Gerontologist, 37: 433-440.

Rowe J. W., Kahn R. L., (2015), Successful Aging 2.0: Conceptual Expansions for the 21st Century, The Journals of Gerontology: Series B, 70 (4):593-596.

Rudman, D. L. (2015). Embodying positive aging and neoliberal rationality: Talking about the aging body within narratives of retirement. Journal of Aging Studies, 34: 10-20.

Sao Jose, J. M. S., Timonen, V., Amado, C., Santos, S. P. (2017). A critique of the Active Ageing Index. Journal of Aging Studies. 40:49-56. DOI: 10.1016/j.jaging.2017. 01.001.

Silverstein M., Parker M. G. (2002). Leisure Activities and Quality of Life among the Oldest Old in Sweden. Research on Aging. 24(5):528-547. doi:10.1177/0164 027502245003.

Stebbins, R.A. (1982). Serious Leisure: A conceptual statement. The Pacific Sociological Review, 25 (2): 251-272.

Stebbins, R.A. (1997). Casual Leisure: A conceptual statement. Leisure Studies, 16 (1): 17-25.

Stebbins, R.A., (2006). Serious Leisure: A perspective for Our Time. Ney Jersey: Transaction Publisher.

Timonen, V. (2016). Beyond Successful and Active Ageing: A Theory of Model Ageing. Bristol, UK: Policy Press.

Walker, A., Foster, L. (2014). The Politicam Economy of Ageing and Later Life. UK: Edward Elgar Publishing.

Zhang,W., Feng, Q., Lacanienta, J., Zhen, Z. (2017), Leisure participation and subjective well-being: Exploring gender differences among elderly in Shanghai, China, Archives of Gerontology and Geriatrics, 69: 45-54. 